\title{
Nanoeugenol Prevents Apoptotic Damage in Selenite-induced Cataracts in Cultured Lenses From Wistar Rats and in Human Lenticular Epithelial Cell Lines: Molecular Validation
}

\author{
Anand Thiraviyam \\ Bharathidasan University \\ Archana Teresa Philip \\ Institute of Ophthalmology Joseph Eye Hospital \\ Philip Aloysius Thomas \\ Institute of Ophthalmology Joseph Eye Hospital \\ Geraldine Pitchairaj ( $\nabla$ gerryarchup@yahoo.co.in ) \\ Bharathidasan University https://orcid.org/0000-0001-5906-0786
}

\section{Research Article}

Keywords: Cataract, oxidative stress, apoptosis, human lenticular epithelial cells, caspases

Posted Date: March 9th, 2021

DOI: https://doi.org/10.21203/rs.3.rs-260712/v1

License: (c) (1) This work is licensed under a Creative Commons Attribution 4.0 International License.

Read Full License 


\section{Abstract}

Senile cataract is the most common cause of severe visual impairment and blindness. Lenticular epithelial cells apoptosis induced by oxidative stress is a major factor in senile cataract pathogenesis, but there are still many blind nodes in this progress. The aim of the present experiment was to investigate the possibility that nanoeugenol prevents selenite-induced cataractogenesis by regulating the reactive oxygen species (ROS) generation, expressions of apoptotic genes and corresponding proteins. Nanoeugenol found to be inhibited oxidative stress-induced downregulation cytochrome c oxidase subunit I (COX-1), B-cell lymphoma 2 (Bcl-2) genes and upregulation of early growth response protein- 1 (EGR-1), Bcl-2-associated X (Bax), caspase-3, caspase-8 and caspase-9 genes in cultured lenses from Wistar rats. Nanoeugenol significantly reduced oxidative stress-induced cell apoptosis and generation of ROS in human lenticular epithelial cells (HLE-B3 cells). These findings suggested that, nanoeugenol can regulate cataract progression by influencing cell vitality and apoptosis, which could provide new ideas for the clinical treatment of senile cataract.

\section{Introduction}

Free radical-induced oxidative stress is postulated to be, perhaps, the key factor leading to senile cataract formation [1]. Oxidative stress-induced apoptosis in lenticular epithelial cells plays a key role in cataract formation, and its prevention is of therapeutic [2]. Apoptosis, or programmed cell death, is the most common form of physiological cell death; it is characterized by the presence of DNA condensation in the nuclei, DNA fragmentation at the nucleosome linkage regions, and cell shrinkage, and ultimately results in the formation of apoptotic bodies [3]. Apoptosis is triggered by a number of physiological and pathological stimuli, including external signals such as hormonal stimulation [4], withdrawal of growth factors [5], viral infection [6], and oxidative stress [7].

In oxidative stress-mediated apoptosis, there is disruption of mitochondrial membranes, release of cytochrome $\mathrm{C}$ (Cyt-c) from the mitochondria and subsequent activation of the caspase-mediated apoptotic pathway [8]. Two representative proteins of the B-cell lymphoma (Bcl) family that restrain or promote apoptosis, namely B-cell lymphoma 2 (Bcl-2) and Bcl-2-associated X (Bax), are thought to play key roles in regulating the effect of mitochondrial membrane permeability, mitochondrial function and Cyt-c release [9]. Normal and selenite cataract lenses were found to vary in the expression of 91 different [10], with the most noticeable variations being noted in the cytochrome c oxidase subunit I (COX-I) (expression of this gene was found to be decreased in selenite cataractous lenses) and in the early growth response protein- 1 (EGR-1) gene (expression of this gene was found to be increased in selenite cataractous lenses) [11]. Interestingly, EGR-1 and COX-I are involved in lenticular apoptosis [11]. Caspases are crucial mediators of apoptosis. Among them, caspase-3 is a frequently activated death protease, which catalyzes the specific cleavage of many key cellular proteins [12]. Caspase- 3 is activated by caspase- 9 and both are involved in the mitochondria-dependent pathway. Caspase-8 lies at the apex of an apoptotic cascade and initiates proteolytic activation of downstream caspase family members, resulting in apoptosis $[13,14]$. 
Lenticular epithelial cell apoptosis has been documented to play a significant role in age-related (senile) cataracts and chemical-induced cataracts under experimental conditions [15]. Previous studies have also shown that lenticular epithelial cell apoptosis can disrupt normal lenticular homeostasis and transparency of lenticular fiber cells, thereby triggering cataractogenesis $[2,16,17]$.

In recent years, nanoparticles have emerged as potentially useful modalities for administration of important medicinal compounds to the eye. This is because nanoparticles, compared to conventional drugs, possess several key advantages, including a large surface area, good tissue penetration and improved bioavailability, with enhanced aqueous solubility and targeted drug-delivery to a specific location in the eye [18]. Our earlier study suggest that nanoeugenol is more effective than plain eugenol in preventing oxidative stress-induced cataractogenesis in an in-vitro experimental model (communicated). In the present study, a description is provided of a study to assess the potential of nanoeugenol to modulate changes in the expression of apoptotic-cascade components, and to regulate lenticular apoptosis in an in-vitro model, and to modulate apoptosis in human lenticular epithelial-B3 (HLE-B3) cells.

\section{Materials And Methods 2.1. Chemicals}

Sodium selenite was obtained from LOBA Chemie (Mumbai, India), and Dulbecco's modified Eagle's medium (DMEM) and the antibiotics streptomycin and penicillin were obtained from HiMedia (Mumbai, India). Antibodies were used to detect EGR-1 (Santa-Cruz, Paso Robles, CA, USA), COX-1 (Cayman, Ann Arbor, MI, USA), Bcl-2 (Santa-Cruz, Paso Robles, CA, USA), Bax (Santa-Cruz, Paso Robles, CA, USA), caspase-3 (Sigma, St. Louis, MO, USA), caspase-8 (Cell Signaling Technology, Beverly, MA, USA), caspase9 (Santa-Cruz, Paso Robles, CA, USA) and $\beta$-actin (Sigma, St. Louis, MO, USA). Anti-rabbit immunoglobulin (IgG) secondary antibody was obtained from Genei (Bengaluru, India). All other chemicals and reagents were of analytical grade. Milli-Q water (Millipore, Bengaluru, India) was used throughout the experiments.

\subsection{In vitro phase of the study}

The animal experiments in the present study were conducted to comply with guidelines of the Committee for the Purpose of Control and Supervision on Experiments on Animals (CPCSEA) and protocols approved by the Association for Research in Vision and Ophthalmology (ARVO); the study protocols were approved by the Institutional Animal Ethical Committee (IAEC; Approval No. BDU/IAEC/P23/2018/24/07.08.2018). Wistar rats (Rattus norvegicus; 75-90 g in weight) were anesthetized with diethyl ether and then sacrificed by cervical dislocation. The lens of each eye was dissected out carefully and then immersed in $3 \mathrm{ml}$ of Dulbecco's modified Eagle's medium (DMEM) (supplemented with fetal calf serum [10\%] and sodium bicarbonate $[0.9 \mathrm{~g} / \mathrm{L}])$ in a 12-well Falcon plastic culture plate. Streptomycin $(60 \mu \mathrm{g} / \mathrm{ml})$ and penicillin $(60 \mu \mathrm{g} / \mathrm{ml})$ were also added to avoid microbial contamination. After incubation for $2 \mathrm{~h}$, opaque lenses were removed from the set-up; only lenses manifesting complete transparency were chosen for 
subsequent experimental studies. The selected lenses were placed in DMEM and were assigned to four groups:

1. Group I $(n=8)$ lenses were cultured in DMEM alone (normal control);

2. Group II $(n=8)$ lenses were cultured in DMEM with sodium selenite only $(100 \mu M$ selenite/ml DMEM) (selenite only);

3. Group III $(n=8)$ lenses were cultured in DMEM with sodium selenite $(100 \mu M$ selenite/mI DMEM) and plain eugenol ( $250 \mu \mathrm{M} / \mathrm{ml}$ DMEM) (eugenol-treated);

4. Group IV ( $(n=8)$ lenses were cultured in DMEM with sodium selenite ( $100 \mu \mathrm{M}$ selenite/ml DMEM) and eugenol-loaded chitosan nanoparticles (nanoeugenol) $(150 \mu \mathrm{M} / \mathrm{ml}$ DMEM) (nanoeugenol-treated).

These lenses were cultured for $24 \mathrm{~h}$ at $37^{\circ} \mathrm{C}$ in cell culture test plates placed in an incubator with $5 \% \mathrm{CO}_{2}$. At the end of $24 \mathrm{~h}$, all lenses were subjected to gross morphological examination, and then processed for DNA fragmentation assay and other molecular investigations.

\subsubsection{DNA fragmentation assay}

DNA was extracted from entire lenses in each group. The fragmentation assay was performed as described by [19], with minor modifications. Briefly, the lenses were homogenized in $500 \mu l$ extraction buffer (10 mM Tris, pH 8.0; $10 \mathrm{mM}$ EDTA, pH 8.0; $75 \mathrm{mM} \mathrm{NaCl} ; 0.5 \%$ SDS and $150 \mu \mathrm{g} / \mathrm{ml}$ proteinase $\mathrm{K}$ [Sigma-Aldrich, St. Louis, MO, USA]) and then incubated at $55^{\circ} \mathrm{C}$ for $3 \mathrm{~h}$. After incubation, the sample was centrifuged for $20 \mathrm{~min}$ at room temperature. DNA was precipitated from the resulting supernatant using 2 volumes of $100 \%$ ethanol with $0.1 \mathrm{M} \mathrm{NaCl}$. The precipitated DNA was washed with $70 \%$ ethanol and then treated with RNase for 60 mins. The residual DNA sample was electrophoresed at $50 \mathrm{~V}$ in a $2 \%$ agarose gel containing ethidium bromide.

\subsubsection{Molecular investigations}

\subsubsection{Reverse transcription-polymerase chain reaction (RT-PCR) analysis of expression of genes encoding lenticular apoptotic cascade proteins}

RNA was isolated by homogenizing cultured lenses from Groups I, II, III and IV with TRIzol (Sigma-Aldrich, St. Louis, MO, USA) reagent ( $1 \mathrm{ml} / 100 \mathrm{mg}$ tissue) as per the manufacturer's instructions. RNAs were quantified using a spectrophotometer at $260 \mathrm{~nm}$; RNA integrity was assessed by measuring $18 \mathrm{~S}$ and $28 \mathrm{~S}$ band intensities via agarose gel electrophoresis.

RT-PCR was performed using a one-step RT-PCR kit (Qiagen, Venlo, Netherlands), as per the manufacturer's instructions. Briefly, $1 \mu \mathrm{g}$ of template RNA and $0.6 \mu \mathrm{M}$ of each of the forward and reverse primers specific to: the apoptotic cascade genes, namely Bcl-2, Bax, caspase-3, caspase- 9 and caspase-8, to related genes such as EGR-1 and $C O X-1$, and also to glyceraldehyde 3-phosphate dehydrogenase 
(GAPDH, the housekeeping gene; Table 1), were placed in a flat-cap PCR tube (Thermo Fisher Scientific, Waltham, MA, USA) along with the enzyme mix (reverse transcriptase and Taq DNA polymerase). Sterile water was added according to the volume of reaction and mixed thoroughly.

Amplification was done in an Eppendorf thermal cycler (Eppendorf, Hamburg, Germany). The RT-PCR conditions were as follows: (1) reverse transcription, $30 \mathrm{~min}, 50^{\circ} \mathrm{C}$, (2) initial PCR activation step, $15 \mathrm{~min}$, $95^{\circ} \mathrm{C}$ and (3) three-step cycling for 30 cycles, each cycle consisting of denaturation for $30 \mathrm{~s}$ at $94^{\circ} \mathrm{C}$ followed by annealing for $30 \mathrm{~s}$ at $59^{\circ} \mathrm{C}$ and extension for $1 \mathrm{~min}$ at $72{ }^{\circ} \mathrm{C}$. The concentration of the template and the number of cycles were optimized to ensure linearity of response and to avoid saturation of the reaction.

After the completion of the PCR reaction, a $10 \mu$ portion of the PCR product was electrophoresed in a $2 \%$ agarose gel. The ethidium bromide-stained gel was photographed with a DS-34 type Polaroid camera and the band was scanned with an imaging densitometer (Bio-Rad, Hercules, CA, USA). The GAPDH gene was used as an internal standard for the RT-PCR reaction. To quantitate the transcript level, the ratio of the study gene product to the GAPDH gene product was calculated. Experiments were performed in replicate.

\subsubsection{Immunoblot analysis}

Sodium dodecyl sulfate-polyacrylamide gel electrophoresis (SDS-PAGE) was performed on $10 \%$ gels using the Tris-glycine buffer system, essentially as described by Laemmli [20]. Immunoblotting for Bcl-2, Bax, caspase-3, caspase-8, caspase-9, EGR-1, COX-I, and $\beta$-actin proteins was performed by electro transferring proteins from the SDS-PAGE gel onto a nitrocellulose membrane $(0.45 \mathrm{~mm}$ pore size, Bio-Rad, Hercules, CA, USA) using a semidry blotting apparatus (Bio-Rad, Hercules, CA, USA). Blotting was done at $30 \mathrm{~V}$ (constant) for $100 \mathrm{~min}$ at an ice-cold temperature using Tris-glycine buffer (12 mM Tris, $96 \mathrm{mM}$ glycine, 20\% methanol) [21] and subsequent blocking was done with $5 \%$ non-fat milk powder in Tris buffer saline (pH 7.5). Specific antibodies against Bcl-2 (1:200 dilution), Bax (1:200 dilution), caspase-3 (1:1000 dilution), caspase-8 (1:500 dilution), caspase-9 (1:200 dilution), EGR-1 (1:200 dilution), COX-1 (1:1000 dilution), and $\beta$-actin (1:3000 dilution) were used, and alkaline phosphatase conjugated to antirabbit lgG secondary antibody was used at a 1:2000 dilution. Immunoreactivity was visualized with 5bromo-4-chloro-3-indolyl phosphate and nitroblue tetrazolium (BCIP/NBT; Genei, Bengaluru, India). The blots developed were finally scanned in a gel documentation system to determine the intensity of the bands (Quantity One Software; Bio-Rad, Hercules, CA, USA).

\subsection{Culture and experimental groups of human lenticular epithelial-B3 (HLE-B3) cells}

Human lenticular epithelial B3 (HLE-B3) cells were a kind gift from Aravind Eye Research Foundation, Madurai, Tamil Nadu, India. Cells were cultured in DMEM supplemented with $20 \%$ fetal bovine serum (Invitrogen-Gibco, Waltham, MA, USA) and $50 \mathrm{\mu g} / \mathrm{ml}$ gentamicin (Invitrogen-Gibco, Waltham, MA, USA) at $37^{\circ} \mathrm{C}$ in a humidified $5 \% \mathrm{CO}_{2}$ atmosphere. The HLE-B3 cells were divided into three main groups:

1. Group I (control cells), comprising cells cultured in DMEM alone; 
2. Group II (selenite only cells), comprising cells cultured in DMEM that contained only sodium selenite (16 $\mu \mathrm{M}$ selenite/ml of DMEM); and

3. Group III (nanoeugenol-treated cells), comprising cells cultured in DMEM containing sodium selenite $(16 \mu \mathrm{M}$ selenite/ml of DMEM) and nanoeugenol ( $80 \mu \mathrm{M} / \mathrm{ml}$ of DMEM).

\subsubsection{Assay for detecting ROS generation}

ROS generation in the HLE-B3 cells was assessed by a fluorescence microscope (Floid Cell Imaging fluorescence microscope, Thermo Fisher Scientific, Waltham, MA, USA). For measuring the total ROS level in the cells, $5 \times 10^{5}$ cells were seeded on a cover-slip in a 6-well plate and allowed to attach overnight. The next day, the cell culture medium was replaced by fresh DMEM alone (Group I; control), by DMEM containing sodium selenite ( $16 \mu \mathrm{M}$ selenite/ml of DMEM) (Group Il; selenite only cells) or by DMEM containing simultaneously-added sodium selenite ( $16 \mu \mathrm{M}$ selenite/ml of DMEM) and nanoeugenol (80 $\mu \mathrm{M} / \mathrm{ml}$ of DMEM) (Group III; nanoeugenol-treated cells). The cells were then incubated for $24 \mathrm{~h}$, following which the cover-slip was removed from the culture plate and stained with $40 \mathrm{mM}$ dichloro-dihydrofluorescein diacetate (DCFH-DA, Sigma-Aldrich, St. Louis, MO, USA) for $30 \mathrm{~min}$. The stained cover slip was washed with $1 \mathrm{X}$ phosphate buffered saline (PBS) to remove extra dye, and then fixed on a glass slide. Images of the cells were captured using 40x objectives of the fluorescence microscope.

\subsubsection{Assay for detection of apoptotic cell death by acridine orange/ethidium bromide (AO/EB) staining}

For measuring apoptotic cell death in the HLE-B3 cells, $5 \times 10^{5}$ cells were seeded on a cover slip in a 6 -well plate and allowed to attach overnight. The next day, the cell culture medium (DMEM) was replaced as described earlier for the experimental groups. The cells were then incubated for $24 \mathrm{~h}$, following which the cover slip was removed from the culture plate and stained with $50 \mu \mathrm{l} / \mathrm{ml}$ of $\mathrm{AO} / \mathrm{EB}$, and incubated at $37^{\circ} \mathrm{C}$ with $5 \% \mathrm{CO}_{2}$ for $30 \mathrm{~min}$. The stained cover slip was washed with $1 \times$ PBS to remove extra dye, and then fixed on a glass slide. Images of the cells were captured using 40x objectives of the fluorescence microscope (Floid Cell Imaging fluorescence microscope, Thermo Fisher Scientific, Waltham, MA, USA).

\subsection{Statistical analysis}

The values are documented as mean \pm the standard deviation of multiple readings. The statistical significance of differences between groups was calculated by One-Way Analysis of Variance (ANOVA) using Statistical Package for Social Sciences (SPSS) software package for Windows, version 21, IBM Corporation, Armonk, NY, USA. Where one-way ANOVA yielded significant results, post-hoc testing was performed for inter-group comparisons using the least significant difference test. Values of $P<0.05$ were deemed statistically significant (highlighted by distinct symbols in figures). 
Table 1

In-vitro study on Wistar rat lenses cultured for $24 \mathrm{~h}$ in Dulbecco's modified Eagle's medium: primer sequences and expected product sizes for the genes amplified.

\begin{tabular}{|c|c|c|c|}
\hline S. No. & Name of the gene & Primer sequence & Size of the amplicon \\
\hline \multirow[t]{2}{*}{1.} & \multirow[t]{2}{*}{$E G R-$} & 5' - ССТСCСАTCACCTATACTGGCC - 3' & \multirow[t]{2}{*}{76 bps } \\
\hline & & 5' -GGGGTTCAGGCCACAAAGTG- 3' & \\
\hline \multirow[t]{2}{*}{2.} & \multirow[t]{2}{*}{$\operatorname{cox}-1$} & 5' - TTCATCCGAGAAGTACTCATG - 3' & \multirow[t]{2}{*}{306 bps } \\
\hline & & 5' - CTGGTGGGTGAAGTGTTGTGC- 3' & \\
\hline \multirow[t]{2}{*}{3.} & \multirow[t]{2}{*}{$B C l-2$} & 5' -TCTCATGCCAAGGGGGAAAC - 3' & \multirow[t]{2}{*}{$130 \mathrm{bps}$} \\
\hline & & $5^{\prime}$-CCACGGCCGAAAGAGAGAAA- 3' & \\
\hline \multirow[t]{2}{*}{4.} & \multirow[t]{2}{*}{ Bax } & 5' - TTTCCTACTTCGGGACCCCC - 3' & \multirow[t]{2}{*}{$101 \mathrm{bps}$} \\
\hline & & 5' -GAAGCCTCAGCCCATCTTCTT- 3' & \\
\hline \multirow[t]{2}{*}{5.} & \multirow[t]{2}{*}{ Caspase-3 } & 5'-GTTCATGTGTATGTTTTATAAG- 3' & \multirow[t]{2}{*}{432 bps } \\
\hline & & 5'-GTCCATGGAATTTAACCTCT- 3' & \\
\hline \multirow[t]{2}{*}{6.} & \multirow[t]{2}{*}{ Caspase-8 } & 5' -GGATTTGAAATCTTTTAAGTT- 3' & \multirow[t]{2}{*}{297 bps } \\
\hline & & 5' -GGCGAGTCCCACATGTCCTGCA- 3' & \\
\hline \multirow[t]{2}{*}{7.} & \multirow[t]{2}{*}{ Caspase-9 } & 5' - GAGGTATTTTGGTAACCACG- 3 & \multirow[t]{2}{*}{$287 \mathrm{bps}$} \\
\hline & & 5' - GTGGAGCATCCCATAAATGCA- 3 & \\
\hline \multirow[t]{2}{*}{8.} & \multirow[t]{2}{*}{$G A P D H$ (internal control) } & 5'- TCAAGAAGGTGGTGAAGCAGGC - 3' & \multirow[t]{2}{*}{207 bps } \\
\hline & & 5'- TTCAGTTACTCTCAAGAGCCA - 3' & \\
\hline
\end{tabular}

\section{Results}

\subsection{Analysis of DNA fragmentation}

To validate the occurrence of apoptosis in Wistar rat lenses, a DNA fragmentation assay was performed by subjecting the DNA sample to agarose gel electrophoresis. DNA fragmentation in lenticular tissue samples of selenite only (Group II) lenses was inferred by the appearance of a number of low-molecular weight bands with a specific laddering pattern, which is recognized as a typical feature of apoptosis (Fig. 1). However, such a "ladder" pattern was not observed in the DNA samples of lenticular tissue of eugenol-treated (Group III) lenses as well as of nanoeugenol-treated (Group IV) lenses. Interestingly, the intact DNA was more prominent in nanoeugenol-treated lenses than in eugenol treated lenses (Fig. 1).

\subsection{Molecular investigations}




\subsubsection{Inferred effects of nanoeugenol on mRNA transcript levels of the apoptotic-cascade component genes and related genes}

The mean levels of mRNA transcripts of the EGR-1, Bax, caspase-3, caspase-8 and caspase-9 genes in selenite only (Group II) lenses were significantly $(P<0.05)$ higher than those noted in normal control (Group I) lenses, in plain eugenol (Group III)-treated lenses and in nanoeugenol (Group IV)-treated lenses (Figs. 2 and 3). Interestingly, the mean mRNA transcript levels of these genes in the nanoeugenol-treated lenses approached the mean values noted in normal control lenses (Figs. 2 and 3). The mean mRNA transcript levels of the COX-1 and $B c /-2$ genes were significantly $(p<0.05)$ lower in Group II lenses than those observed in Group I, Group III and Group IV lenses (Fig. 2). Treatment with nanoeugenol appeared to be more effective than treatment with plain eugenol in maintaining the mean mRNA transcript levels of the $C O X-1$ and $B C l-2$ genes at near control (normal) levels (Fig. 2).

\subsubsection{Effects of nanoeugenol on the levels of apoptotic- cascade proteins}

To corroborate the data (provided above) obtained from RT-PCR analysis of the apoptotic-cascade component genes and related genes, immunoblotting was performed to detect and quantitate the level of expression of the corresponding proteins. Immunoblot analysis revealed significantly $(P<0.05)$ higher mean band intensities of the EGR-I and Bax (Fig. 4) proteins in selenite only (Group II) lenses than those in normal control (Group I) lenses, eugenol-treated (Group III) and nanoeugenol-treated (Group IV) lenses (Fig. 4). Conversely, lower mean band intensities of the COX-1 and Bcl-2 proteins were observed in Group II lenses than those in Group I, Group III and Group IV lenses (Fig. 4). The mean levels of these proteins in Group III and in Group IV lenses approached the mean levels noted in the control (Group I) lenses (Fig. 4).

Possible proteolytic processing of procaspase-3 was evaluated by Western blotting using a monoclonal antibody to caspase-3 (Fig. 5). This revealed a band at $32 \mathrm{kDa}$, which was interpreted as being uncleaved caspase-3; this was most intense in samples from control (Group I) lenses (Fig. 5). In selenite only (Group II) lenses, an additional band was present at $17 \mathrm{kDa}$, which was possibly a fragment of cleaved caspase3. However, in protein samples from eugenol-treated (Group III) lenses, such fragments were drastically reduced, while in samples from nanoeugenol-treated (Group IV) lenses, such fragments were not observed at all (Fig. 5). Interestingly, the band at $32 \mathrm{kDa}$ was more intense in Group IV lenses than that noted in Group III lenses.

Putative changes in the basal profile of effector caspase proteins were sought in the cultured lenses by Western blotting analysis. In selenite only (Group II) lenses, there appeared to be activation of caspase-8, since there was a reduction in the intensity of what was inferred to be a $55 \mathrm{kDa}$ band, with the simultaneous appearance of a $42 \mathrm{kDa}$ fraction, which was inferred to have been cleaved from the $55 \mathrm{kDa}$ product (Fig. 5). However, in protein samples from eugenol-treated (Group III) and from nanoeugenol- 
treated (Group IV) lenses, such activation appeared to have been prevented, which was inferred from the absence of the $42 \mathrm{kDa}$ fragment. Interestingly, the basal profile of effector caspase proteins in Group IV lenses approximated that seen in cultured normal (Group I) lenses (Fig. 5).

To understand the possible involvement of the mitochondrial apoptotic pathway, the mean level of caspase-9 protein was also determined, since it has been reported that procaspase-9 (45 kDa), upon activation, cleaves into a fragment of approximately $35 \mathrm{kDa}$. Such cleavage appeared to occur in samples from the selenite only (Group II) lenses (Fig. 5). However, in eugenol-treated (Group III) lenses and in nanoeugenol-treated (Group IV) lenses, there did not appear to be any such activation of procaspase-9 since there was no cleaved fragment of $35 \mathrm{kDa}$ (Fig. 5).

\subsection{Effect of nanoeugenol on ROS generation in HLE-B3 cells}

The intensity of ROS generation induced by sodium selenite was morphologically examined using DCFHDA staining. Intense green fluorescence, a sign of ROS generation, was noted in Group II (selenite only) cells; only minimal green fluorescence was noted in Group I (normal control) cells (Fig. 6). Interestingly, in the cells that had been challenged with selenite and treated with nanoeugenol (Group III), minimal intensity of green fluorescence was observed (Fig. 6), suggesting that ROS generation was prevented in these cells.

\subsection{Effect of nanoeugenol on prevention of apoptotic cell death in HLE-B3 cells stained with AO/EB}

To determine the apoptosis-associated changes of cell membranes in HLE-B3 cells, the AO/EB fluorescence staining method was adopted. Selenite only (Group II) cells stained by AO/EB exhibited morphological characteristics of non-viable cells, with cell shrinkage, impaction of nuclei, chromatin condensation and nuclear fragmentation all being noted; normal control (Group I) and nanoeugenoltreated (Group III) cells did not exhibit such characteristics (Fig. 7). In Group II cells, nuclei which had undergone condensation of chromatin fluoresced uniformly as bright-red or orange. Interestingly, the selenite-challenged cells that had been treated with nanoeugenol did not exhibit such fluorescence; this suggests that treatment with nanoeugenol prevented the condensation of chromatin noted in Group II cells and permitted maintenance of morphology of the cells at near-normal levels (similar to control cells that fluoresced green [Fig. 7]).

\section{Discussion}

Apoptotic cell death, an essential and natural process that occurs in all tissues under both physiological and pathological conditions, mainly acts to eliminate cellular wastes [22]. However, under certain conditions, apoptosis may actually kill cells, resulting in various pathological conditions, including cataract. The results of a previous study [23] suggested that normal lenticular epithelial cells exhibited less apoptosis than did cataractous cells. Thus, lenticular epithelial cell apoptosis may be a common 
cellular basis for the initiation of non-congenital cataract formation. Apoptosis, the end-result of cataractogenesis, is also believed to arise due to stimuli such as calcium influx, oxidative stress, hypoxia, heat, and ionizing radiation [24]. Therefore, prevention of cataractogenesis by medical means seeks to inhibit oxidative stress and apoptosis in lenticular epithelial cells.

In the present study, a DNA fragmentation assay of genomic DNA from selenite only (Group II) lenses revealed the characteristic "laddering" pattern that has been reported to occur in apoptotic cell death. A similar "laddering" pattern has also been noted in DNA samples of lenticular tissue from patients with anterior polar cataract [25]. This "laddering" is believed to be due to internucleosomal $\mathrm{Ca}^{2+}-\mathrm{Mg}^{2+}$ dependent endonuclease-mediated cleavage [26]. It has previously been reported that calcimycin initiates epithelial cell apoptosis in lens organ culture [23]. In the current study, such "laddering" was drastically reduced in eugenol-treated lenses and not seen at all in nanoeugenol-treated lenses. Moreover, genomic DNA appeared to be intact in the nanoeugenol-treated lenses, as noted in control lenses (Fig. 1). This result is consistent with earlier observations wherein doxorubicin-loaded methyl ether-poly ethylene glycol nanoparticles prevented DNA damage more efficiently than did the free drug in preventing posterior capsular opacification in New Zealand white rabbits [27].

Elevated intracellular calcium results in activation of calpain in selenite cataractous lenses. It has been documented that chrysin modulates these effects and therein retards experimental selenite cataractogenesis [28]. Hence, in the present study, an attempt was made to investigate whether this effect of calcium extends up to the activation of the apoptotic pathway, and whether nanoeugenol modulates or blocks the caspase cascade, therein retarding selenite-induced cataractogenesis. This hypothesis was tested by assessing the expression of five essential genes involved in the apoptotic pathway, namely the EGR-1, COX-1, caspase-3, caspase-8 and caspase-9 genes. Freyssenet et al. [29] demonstrated a direct correlation between increased intracellular calcium and upregulation of the gene encoding EGR-1. A similar association appears to have occurred in the present investigation in that selenite only lenses exhibited elevated mean calcium levels (data not shown, communicated) as well as increased expression of the EGR-1 gene (Fig. 2) and the EGR-1 protein (Fig. 4). Nakajima et al. [30] were of the opinion that the loss of epithelial barrier function contributes to an increase in the intracellular calcium pool, therein leading to increased expression of EGR-1. However, in the present investigation, treatment of selenitechallenged lenses with eugenol (Group III) or nanoeugenol (Group IV) appeared to maintain the lenticular mRNA transcript level of EGR-1, and the lenticular concentration of the EGR-1 protein itself, at near normal levels (Figs. 2 and 4). A similar pattern of EGR-1 expression has also been reported following treatment with other antioxidants, such as curcumin in endothelial cells and fibroblasts [31] and acetyl-L-carnitine in selenite-induced cataractous lenses of Wistar rats [32].

Dysfunction of the COX-1 enzyme leads to compromised mitochondrial membrane potential and a decreased ATP level [33]. In the current investigation, selenite only (Group II) lenses have shown significantly lower mean levels of COX-ImRNA transcripts (Fig. 2) and COX-I protein than those in normal control lenses (Fig. 4). Decreased expression of COX-I has also been noted in selenite-cataractous lenses $[11,32]$ and in UPL rats [34]. Yang et al. [35] have suggested that down-regulation of COX-1 might result in 
decreased synthesis of ATP. However, in the present study, such a decline in COX-1 expression, both at the transcriptional and translational levels, appears to have been prevented in eugenol-treated and nanoeugenol-treated lenses, suggesting a protective role for these compounds. Similarly, chrysin was found to maintain mRNA transcript levels of $C O X-1$ at near normal levels in lenses challenged with selenite [28].

In apoptosis, there is direct damage to the mitochondria by ROS or indirect mitochondrial depolarization by proapoptotic Bcl-2 family proteins [2]. Bax and Bcl-2 are two important pro-and anti-apoptotic, respectively, proteins [36]. Over-expressed Bax counters the death repressor activity of Bcl-2 and accelerates apoptotic death induced by cytokine deprivation [37]. Bcl-2 is a membrane-bound protein which strongly inhibits apoptosis [38]. Bcl-2 functions as an antiapoptotic protein by forming homo- and heterodimerization with other members of the Bcl-2 family of proteins [39]. In the present study, a significantly $(P<0.05)$ lower mean mRNA transcript level of $B c l-2$ and a higher mean mRNA transcript level of Bax was observed in selenite only (Group II) lenses than the corresponding values in normal control (Group I) lenses (Fig. 2). These expression patterns of $\mathrm{BCl}-2$ and $B a x$ genes in samples from cataractous lenses are similar to those noted in samples from human anterior polar cataract; it was suggested that the lower $B c /-2$ and higher Bax mRNA transcript levels represent an "active" means of cell death in lenticular epithelial cells of anterior polar cataract [25]. In the present study, treatment of selenitechallenged lenses with either plain eugenol or with nanoeugenol appeared to have prevented such alterations in mean mRNA transcript levels of $B a x$ and $B c l-2$; however, this effect was apparent to a greater extent in the nanoeugenol-treated lenses (Fig. 2), suggesting that the regulatory influence of eugenol as a nanoform is superior to that of plain eugenol. The immunoblot results of $\mathrm{Bcl}-2$ and $\mathrm{Bax}$ protein levels in the cultured lenses (Fig. 4) appeared to mirror the RT-PCR results (Fig. 2). Similarly, Pinus densiflora bark extract was found to maintain mRNA transcript levels of $B c l-2$ and $B a x$ at near normal levels in lenses challenged with selenite [40].

Caspases are crucial mediators of apoptosis; they transduce the apoptotic signal cascade and engage cellular targets, leading to programmed cell death [41]. Following activation, both caspase-9 and caspase8 activate procaspase-3, therein forming active caspase-3, an "executioner caspase", which is reported to play a vital role in regulating and executing apoptosis in mammalian cells [42]. The activation of caspase-3 has been shown to be an essential step in multiple apoptotic signaling pathways triggered by different apoptotic signals [43]. In the present study, the mean mRNA transcript levels of the caspase-3, caspase-8, and caspase-9 genes in selenite only (Group II) lenses were found to be significantly higher than those in the normal control (Group I), plain eugenol-treated (Group III) and nanoeugenol-treated (Group IV) lenses (Fig. 3). In order to confirm the above finding at the translational level by detection of the proteins, specific antibodies were used. In samples of selenite only lenses, the band intensity of caspase- 3 was higher than that seen in samples of cultured normal control lenses; a proteolytic fragment of active caspase-3 (17 kDa) was also noted. However, in samples of Group III and Group IV lenses, the band intensity of caspase-3 protein was similar to that noted in normal control lenses; moreover, the proteolytic fragment (active form) was present in traces (Group III) or not at all (Group IV) (Fig. 5). This suggests that activation of caspase-3 was prevented in Group III and Group IV lenses, possibly due to the 
antiapoptotic potential of plain eugenol and nanoeugenol (Fig. 5). The results of the present study are similar to those obtained in studies on mRNA transcript and protein levels of caspase 3 in selenitechallenged rat pups that had been treated with a Pinus densiflora bark extract, to prevent selenite-induced oxidative stress and apoptosis [40].

Caspase-8, one of the initiator caspases responsible for the activation of the effector caspases (caspase$3,-6$ and -7 ), plays a pivotal role in the extrinsic apoptotic signaling pathway via death receptors [44]. In the present study, caspase- 8 was found to be activated in selenite only lenses, as suggested by the presence of a cleaved fragment of $42 \mathrm{kDa}$ (Fig. 5). However, in plain eugenol-treated (Group III) and in nanoeugenol-treated (Group IV) lenses, the activation of caspase-8 appeared to have been prevented, as there was absence of these $42 \mathrm{kDa}$ fragments (Fig. 5). Procaspase-9 (approximately $45 \mathrm{kDa}$ ), upon activation, is reported to cleave into fragments of approximately $35 \mathrm{kDa}[45,46]$. In the present set of experiments, a similar activation of procaspase- 9 was also noted in samples from selenite only lenses which showed cleaved fragments of approximately $35 \mathrm{kDa}$ (Fig. 5). However, nanoeugenol treatment (in Group IV lenses) appeared to prevent such activation, and hence it appeared as intact procaspase-9 (Fig. 5). The results obtained in the current investigation are similar to those of an earlier study [47].

Thus, the results of molecular investigation of apoptotic-related genes in the current study suggest that nanoeugenol protects against apoptotic cell death in lenticular cells of selenite-challenged lenses by reducing or blocking the activation of the apoptotic cascade, thereby preventing caspase-mediated cell death. Numerous antioxidants have been reported to possess anti-apoptotic properties in various animal models; these include quercetin [48], beta-carotene [49], acetyl- L-carnitine [32], melatonin [50] and extract of leaves of Nerium oleander [51].

Death of lenticular epithelial cells interrupts the lifelong growth of the human lens, therein contributing to the thinness of cataractous lenses $[10,23]$ and to the lower density of epithelial cells in cataractous lenses $[52,53]$. Excessive ROS production in oxidative stress is significantly implicated in mitochondrial damage and cell death $[54,55]$. Substantial evidence suggests that exposure to selenite in experimental animal models of cataract leads to increased generation of ROS $[40,56]$. So also, in the present investigation, ROS generation appeared to be significantly higher in selenite only (Group II) cells than that in control (Group I) and that in nanoeugenol-treated (Group III) cells, as assessed by DCFH-DA staining (Fig. 6). These results suggest that due to the elevation of ROS levels, oxidative stress occurs in HLE-B3 cells exposed to selenite. Interestingly, simultaneous nanoeugenol treatment of such selenite-challenged cells (Group III) appeared to effectively prevent excessive ROS production, and ROS levels were maintained at near-normal (Fig. 6). So also, Zhou et al. [57] reported, that excessive ROS generation induced by $\mathrm{H}_{2} \mathrm{O}_{2}$ in HLE-B3 cells was prevented by rutin, an antioxidant.

Apoptosis of lenticular epithelial cells appears to be a common cellular basis for the initiation and progression of non-congenital cataracts in humans and animals [58]. There appears to be a close relationship between apoptosis of lenticular epithelial cells and cataract formation since death of lenticular epithelial cells due to stress leads to oxidation, hydration and, ultimately, cataract formation 
[59]. Apoptotic cells are characterized by a series of morphological events, including shrinkage in the size of the cells and the nucleus, loss of adhesion to adjacent cells, membrane blebbing, chromatin condensation, and DNA fragmentation [60]. It has been reported that following AO/EB fluorescence staining, the cells that stain green represent viable cells with a highly-organized structure whereas the cells that stain orange/red represent cells in late apoptosis, with condensed or fragmented chromatin [61]. In the present investigation, among the experimental groups of cells that underwent AO/EB staining, the normal (Group I) cells stained green, suggesting viable cells with a highly organized cellular structure (Fig. 7). However, selenite only (Group II) cells revealed intense orange/red fluorescence staining, suggesting that the cells were in the late apoptotic stage with condensed or fragmented chromatin (Fig. 7). Interestingly, the cells that were selenite-challenged and simultaneously treated with nanoeugenol (Group III) exhibited green fluorescence staining with only very few orange/red spots (Fig. 7). This observation clearly suggests that treatment of selenite-challenged cells with nanoeugenol prevented, or greatly minimized, apoptosis of the cells. Thus, nanoeugenol possibly had a protective effect on the selenite-challenged HLE-B3 cells by inhibiting selenite-induced cell apoptosis.

\section{Conclusion}

In conclusion, the results of the present investigation suggest that nanoeugenol, and, to a lesser extent, plain eugenol, confer protection against apoptotic cell death in cultured selenite-challenged, Wistar rat lenses by regulating expression of EGR-1, COX-1, Bcl-2 and Bax, both at the transcriptional and translational levels, and by blocking the activation of the caspase cascade in both the 'extrinsic' and the 'intrinsic' pathways, thereby preventing caspase-mediated DNA damage and cell death. The results also suggest that nanoeugenol confers protection against selenite-induced oxidative damage and apoptosis that would otherwise lead to cataractogenesis in HLE-B3 cells. The observations of the present study strongly suggest that nanoeugenol possesses greater antiapoptotic potential than that of plain eugenol by virtue of its action on the apoptotic-cascade components involved in selenite-induced cataractogenesis.

\section{Declarations}

\section{Compliance with ethical standards}

\section{Conflict of interest}

The authors report no potential conflict of interest relevant to this article.

\section{Funding}

No financial support was received for this submission.

\section{Authors contributions}


T. Anand: Investigation, Conceptualization, Writing - original draft. P. Archana Teresa: Visualization, Investigation. P.A. Thomas: Reviewing and Editing. P. Geraldine: Supervision, Conceptualization, Validation, Reviewing and Editing.

\section{Ethical approval}

Committee for the Purpose of Control and Supervision on Experiments on Animals (CPCSEA) approval (IAEC; Approval No. BDU/IAEC/P23/2018/24/07.08.2018) was granted prior to the study.

\section{Acknowledgments}

Financial support rendered by the University Grants Commission-Basic Scientific Research-Faculty Fellowship (UGC-BSR-FF; Grant No. F. 18-1/2011(BSR) dt.07.10.2014) to the corresponding author is gratefully acknowledged. The instrumentation facility provided by Department of Science and Technology-Fund for Improvement of Science and Technology Infrastructure (DST-FIST)-Level-I (stage-II) (Ref. No. SR/FST/LSI-647/2015(C) Dt.11.08.2016) of the Department of Animal Science, Bharathidasan University, is also acknowledged.

\section{References}

1. Ho MC, Peng YJ, Chen SJ, Chiou SH (2010) Senile cataracts and oxidative stress. J Clin Gerontol Geriatr 1(1): 17-21.

2. Qi B, Ji Q, Wen Y et al (2014) Lycium barbarum polysaccharides protect human lens epithelial cells against oxidative stress-induced apoptosis and senescence. PLoS One 9(10):e110275.

3. Elmore S (2007) Apoptosis: a review of programmed cell death. Toxicol Pathol 35(4):495-516.

4. Kiess W, Gallaher B (1998) Hormonal control of programmed cell death/apoptosis. Eur J Endocrinol 138(5):482-491.

5. Letai A (2006) Growth factor withdrawal and apoptosis: the middle game. Mol cell 21(6):728-730.

6. Groux H, Torpier G, Monte $D$ et al (1992) Activation-induced death by apoptosis in $\mathrm{CD}^{4+} \mathrm{T}$ cells from human immunodeficiency virus-infected asymptomatic individuals. J Exp Med 175(2):331-340.

7. Yao K, Tan J, Gu W-z et al (2007) Reactive oxygen species mediates the apoptosis induced by transforming growth factor $\beta 2$ in human lens epithelial cells. Biochem Biophys Res Commun 354(1):278-283.

8. Kroemer G, Galluzzi L, Brenner C (2007) Mitochondrial membrane permeabilization in cell death. Physiol Rev 87(1):99-163.

9. Zhang L, Yuan X, Wang S et al (2014) The relationship between mitochondrial fusion/fission and apoptosis in the process of adipose-derived stromal cells differentiation into astrocytes. Neurosci Lett 575:19-24.

10. Osnes-Ringen O, Berg KH, Moe MC et al (2016) Cell death pattern in lens epithelium of cataract patients. Acta Ophthalmol 94(5): 514-520. 
11. Nakajima T, Nakajima E, Fukiage C et al (2002) Differential gene expression in the lens epithelial cells from selenite injected rats. Exp Eye Res 74(2):231-236.

12. Porter AG, Jänicke RU (1999) Emerging roles of caspase-3 in apoptosis. Cell Death Differ 6: 99-104.

13. Scaffidi C, Medema JP, Krammer PH et al (1997) Flice is predominantly expressed as two functionally active isoforms, caspase-8/a and caspase-8/b. J Biol Chem 272(43): 26953-26958.

14. Scaffidi C, Schmitz I, Zha J et al (1999) Differential modulation of apoptosis sensitivity in CD95 type I and type II cells. J Biol Chem 274(32): 22532-22538.

15. Okamura N, Ito $\mathrm{Y}$, Shibata MA et al (2002) Fas-mediated apoptosis in human lens epithelial cells of cataracts associated with diabetic retinopathy. Med Electron Microsc 35(4):234-241.

16. Jia Z, Song Z, Zhao Y et al (2011) Grape seed proanthocyanidin extract protects human lens epithelial cells from oxidative stress via reducing NF-KB and MAPK protein expression. Mol Vis 17:210-217.

17. Bai J, Yang F, Dong L, Zheng Y (2017) Ghrelin protects human lens epithelial cells against oxidative stress-induced damage. Oxid Med Cell Longev 1910450.

18. Yu-Wai-Man C, Khaw PT (2015) Developing novel anti-fibrotic therapeutics to modulate post-surgical wound healing in glaucoma: big potential for small molecules. Expert Rev Ophthalmol 10(1):65-76.

19. Prigent $P$, Blanpied C, Aten J et al (1993) A safe and rapid method for analyzing apoptosis-induced fragmentation of DNA extracted from tissues or cultured cells. J Immunol Methods 160(1):139-140.

20. Laemmli (1970) Cleavage of structural proteins during the assembly of the head of bacteriophage T4. Nature 227(5259):680-685.

21. Towbin H, Staehelin T, Gordon J (1979) Electrophoretic transfer of proteins from polyacrylamide gels to nitrocellulose sheets: procedure and some applications. Proc Natl Acad Sci USA 76(9):4350-4354.

22. Shao WH, Cohen PL (2011) Disturbances of apoptotic cell clearance in systemic lupus erythematosus. Arthritis Res Ther 13(1): 202.

23. Li WC, Kuszak JR, Dunn K et al (1995) Lens epithelial cell apoptosis appears to be a common cellular basis for non-congenital cataract development in humans and animals. J Cell Biol 130(1): 169-181.

24. Stadelmann C, Lassmann H (2000) Detection of apoptosis in tissue sections. Cell Tissue Res 301(1):19-31.

25. Lee $\mathrm{EH}$, Wan $\mathrm{XH}$, Song $\mathrm{J}$ et al (2002) Lens epithelial cell death and reduction of anti-apoptotic protein $\mathrm{Bcl}-2$ in human anterior polar cataracts. Mol vis 8:235-240.

26. Yakovlev AG, Wang G, Stoica BA et al (2000) A role of the $\mathrm{Ca}^{2+} / \mathrm{Mg}^{2+}$-dependent endonuclease in apoptosis and its inhibition by poly(adp-ribose) polymerase. J Biol Chem 275(28): 21302-21308.

27. Guha R, Chowdhury S, Palui $\mathrm{H}$ et al (2013) Doxorubicin-loaded MePEG-PCL nanoparticles for prevention of posterior capsular opacification. Nanomedicine (Lond) 8(9): 1415-1428.

28. Sundararajan M, Thomas PA, Teresa PA et al (2016) Regulatory effect of chrysin on expression of lenticular calcium transporters, calpains, and apoptotic-cascade components in selenite-induced cataract. Mol Vis 22:401-423. 
29. Freyssenet D, Irrcher I, Connor MK et al (2004) Calcium-regulated changes in mitochondrial phenotype in skeletal muscle cells. Am J Physiol Cell Physiol 286(5): 1053- 1061.

30. Nakajima T, Belusko PB, Walkup RD et al (2006) Involvement of Egr-1 in lens epithelial cell death induced by selenite. Exp Eye Res 82(5): 874-878.

31. Pendurthi UR, Rao LV (2000) Suppression of transcription factor Egr-1 by curcumin. Thromb Res 97(4): 179-189.

32. Elanchezhian R, Sakthivel M, Geraldine P et al (2009) The effect of acetyl-I-carnitine on lenticular calpain activity in prevention of selenite-induced cataractogenesis. Exp Eye Res 88(5):938-944.

33. Li Y, Park J-S, Deng J-H et al (2006) Cytochrome c oxidase subunit IV is essential for assembly and respiratory function of the enzyme complex. J Bioenerg Biomembr 38(5-6):283-291.

34. Nabekura $\mathrm{T}$, Tomohiro $\mathrm{M}$, Ito $\mathrm{Y}$ et al (2004) Changes in plasma membrane $\mathrm{Ca}^{2+}{ }^{2}$-ATPase expression and ATP content in lenses of hereditary cataract UPL rats. Toxicology 197(2): 177-183.

35. Yang J, Zhu J, Xu WH (2010) Differential expression, phosphorylation of COX subunit 1 and COX activity during diapause phase in the cotton bollworm, Helicoverpa armigera. J Insect Physiol 56(12): 1992-1998.

36. Gahl RF, He Y, Yu S et al (2014) Conformational rearrangements in the pro-apoptotic protein, Bax, as it inserts into mitochondria: a cellular death switch. J Biol Chem 289(47):32871-32882.

37. Pasupuleti N, Matsuyama S, Voss 0 et al (2010) The anti-apoptotic function of human aA-crystallin is directly related to its chaperone activity. Cell Death Dis 1(3):e31-e31.

38. Lindsay J, Esposti MD, Gilmore AP (2011) Bcl-2 proteins and mitochondria-specificity in membrane targeting for death. Biochim Biophys Acta 1813(4): 532-539.

39. Green DR, Reed JC (1998) Mitochondria and apoptosis. Science 281(5381): 1309-1312.

40. Kim J, Choung S-Y (2017) Pinus densiflora bark extract prevents selenite-induced cataract formation in the lens of Sprague Dawley rat pups. Mol Vis 23:638-648.

41. Bantseev V, Youn H-Y. Mitochondrial "movement" and lens optics following oxidative stress from UVB irradiation. Ann N Y Acad Sci. 2006; 1091(1):17-33.

42. Cain K, Bratton SB, Cohen GM (2002) The Apaf-1 apoptosome: a large caspase-activating complex. Biochimie 84(2-3):203-214.

43. Fernandes-Alnemri T, Takahashi A, Armstrong R et al (1995) Mch3, a novel human apoptotic cysteine protease highly related to CPP32. Cancer Res 55(24): 6045-6052.

44. Zandy AJ, Lakhani S, Zheng $T$ et al (2005) Role of the executioner caspases during lens development. J Biol Chem 280(34):30263-30272.

45. Li P, Nijhawan D, Budihardjo I et al (1997) Cytochrome $c$ and dATP-dependent formation of Apaf 1/caspase-9 complex initiates an apoptotic protease cascade. Cell 91(4): 479-89.

46. Zhivotovsky B, Samali A, Gahm A et al (1999) Caspases: their intracellular localization and translocation during apoptosis. Cell Death Differ 6(7):644-651. 
47. Kumari RP, Ramkumar S, Thankappan B et al (2015) Transcriptional regulation of crystallin, redox, and apoptotic genes by C-Phycocyanin in the selenite-induced cataractogenic rat model. Mol vis 21:26.

48. Marchionatti AM, Tolosa de Talamoni N (2009) Antioxidant and antiapoptotic properties of quercetin prevent oxidative stress caused by menadione in chick intestine. Bone 45(6): S157.

49. Peng HC, Chen JR, Chen YL et al (2010) Beta-Carotene exhibits antioxidant and anti apoptotic properties to prevent ethanol-induced cytotoxicity in isolated rat hepatocytes. Phytother Res 24 Suppl 2: S183-S189.

50. Carpentieri A, Marchionatti A, Areco V et al (2014) Antioxidant and antiapoptotic properties of melatonin restore intestinal calcium absorption altered by menadione. Mol Cell Biochem 387(1-2): 197-205.

51. Benson KF, Newman RA, Jensen GS (2015) Antioxidant, anti-inflammatory, anti-apoptotic, and skin regenerative properties of an Aloe vera-based extract of Nerium oleander leaves (nae- $8 \AA$ ). Clin Cosmet Investig Dermatol 8: 239-248.

52. Vasavada AR, Cherian M, Yadav S et al (1991) Lens epithelial cell density and histomorphological study in cataractous lenses. J Cataract Refract Surg 17(6): 798-804.

53. Liu X, Liu Y, Zheng J et al (2000) Lens epithelial cell proliferation and cell density in human agerelated cataract. Yan Ke Xue Bao 16(3): 184-188.

54. Zorov DB, Filburn CR, Klotz LO et al (2000) Reactive oxygen species (ROS)-induced ROS release: a new phenomenon accompanying induction of the mitochondrial permeability transition in cardiac myocytes. J Exp Med.; 192(7):1001-1014.

55. Zorov DB, Juhaszova M, Sollott SJ (2006) Mitochondrial ROS-induced ROS release: An update and review. Biochim Biophys Acta Bioenerg 1757(5-6):509-517.

56. Varma SD, Hegde KR, Kovtun S (2010) Inhibition of selenite-induced cataract by caffeine. Acta Ophthalmol 88(7):e245-e249.

57. Zhou Y-F, Guo B, Ye M-J et al (2016) Protective effect of rutin against $\mathrm{H}_{2} \mathrm{O}_{2}$-induced oxidative stress and apoptosis in human lens epithelial cells. Curr Eye Res 41(7):933-942.

58. Oltulu P, Oltulu R (2018) The association of cataract and lens epithelial cell apoptosis in patients with Pseudoexfoliation syndrome. Curr Eye Res 43(3):300-303.

59. Mulhern ML, Madson CJ, Danford A, et al (2006) The unfolded protein response in lens epithelial cells from galactosemic rat lenses. Invest Ophthalmol Vis Sci 47(9):3951-3959.

60. Mills JC, Stone NL, Pittman RN (1999) Extranuclear apoptosis. The role of the cytoplasm in the execution phase. J Cell Biol 146(4):703-708.

61. Sudha A, Srinivasan P, Kanimozhi V et al (2018) Antiproliferative and apoptosis-induction studies of 5-hydroxy 3',4',7-trimethoxyflavone in human breast cancer cells MCF-7: an in vitro and in silico approach. J Recept Signal Transduct 38(3):179-190. 


\section{Figures}

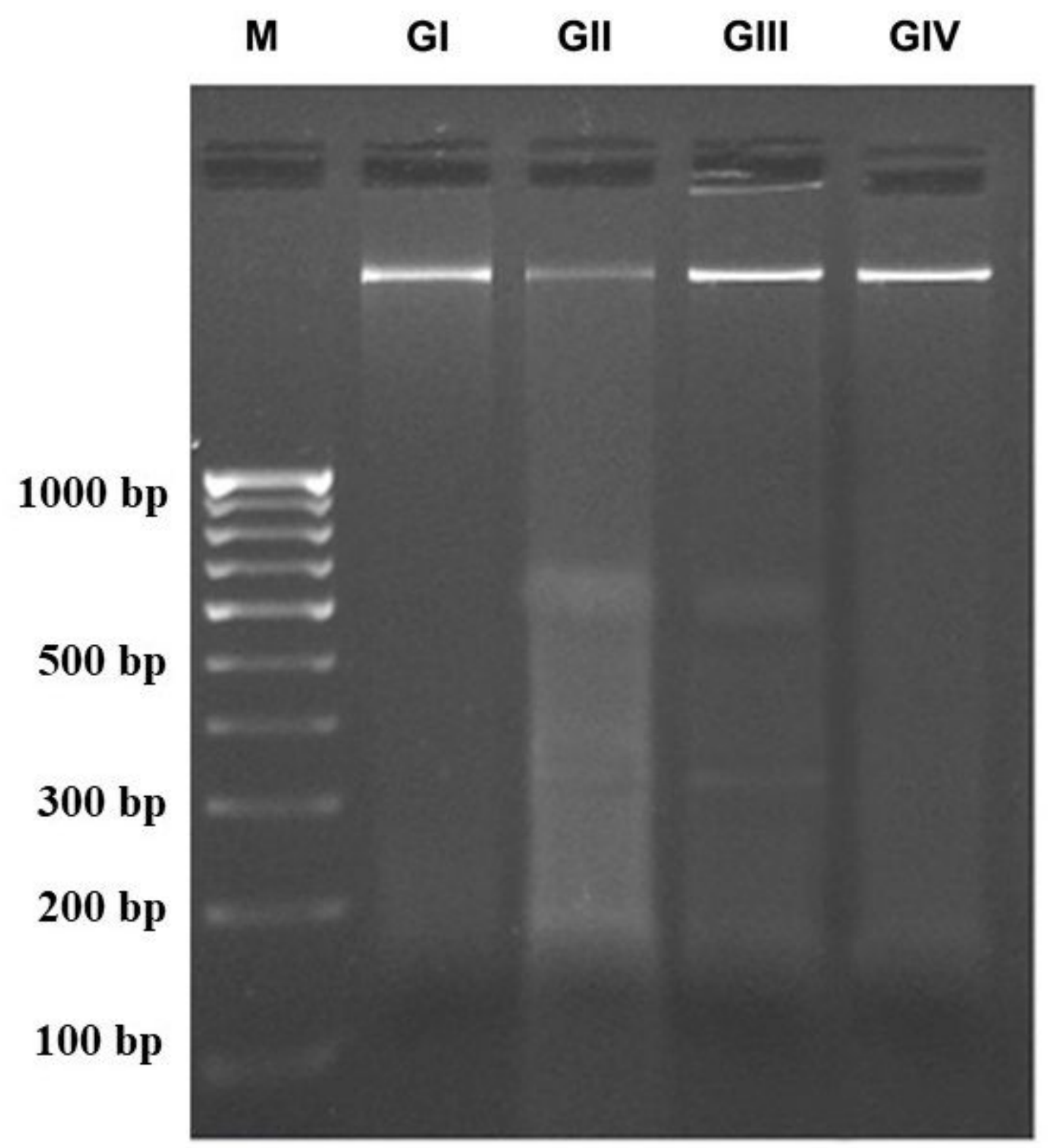

\section{Figure 1}

In vitro study on Wistar rat lenses cultured in Dulbecco's modified Eagle's medium (DMEM): DNA fragmentation patterns in lenticular tissue of different groups of lenses Groups of lenses 1) Group I comprising lenses cultured in DMEM alone (normal control). 2) Group II comprising lenses cultured in DMEM containing sodium selenite only (100 $\mu \mathrm{M}$ selenite/ml DMEM) (selenite only). 3) Group III 
comprising lenses cultured in DMEM containing sodium selenite (100 $\mu \mathrm{M}$ selenite/ml DMEM) and eugenol (250 $\mu \mathrm{M}$ of eugenol/mI DMEM) (eugenol-treated). 4) Group IV comprising lenses cultured in DMEM containing sodium selenite $(100 \mu \mathrm{M}$ selenite/ml DMEM) and nanoeugenol (150 $\mu \mathrm{M}$ of nanoeugenol/ml DMEM) (nanoeugenol-treated).

a)

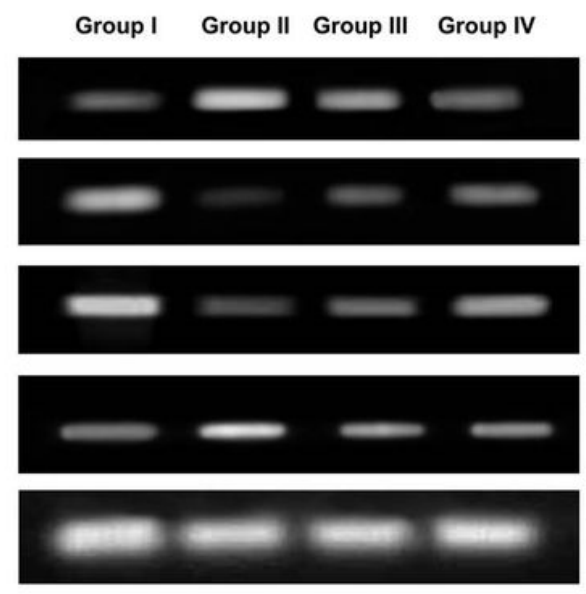

EGR-1 (76 bps)

COX-1 (306 bps)

$\mathrm{BCl}-2$ (130 bps)

Bax (101 bps)

GAPDH (207 bps) b)

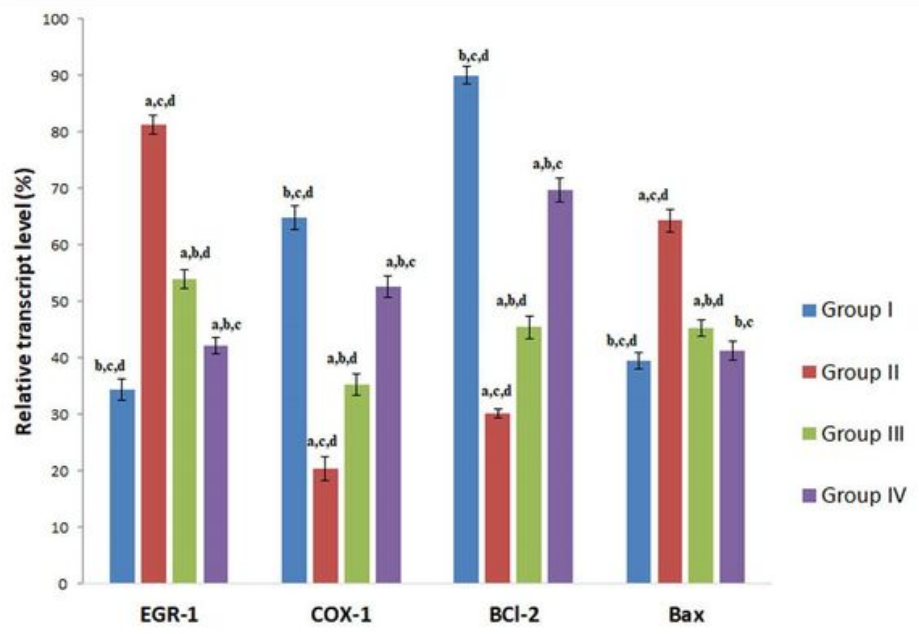

\section{Figure 2}

In-vitro study on Wistar rat lenses cultured for $24 \mathrm{~h}$ in Dulbecco's modified Eagle's medium (DMEM): RTPCR generation of mRNA transcripts of genes encoding apoptotic-cascade component proteins and related proteins in selenite-challenged lenses. a) Ethidium bromide-stained agarose gel showing differential staining intensity of mRNA transcripts of the genes in the four groups of lenses. b) Bar graphs of mean normalised (in relation to GAPDH) densitometry readings of mRNA transcripts of the genes in the four groups of lenses. Groups of lenses 1) Group I comprising lenses cultured in DMEM alone (normal control). 2) Group II comprising lenses cultured in DMEM containing sodium selenite only (100 $\mu \mathrm{M}$ selenite/ml DMEM) (selenite only). 3) Group III comprising lenses cultured in DMEM containing sodium selenite (100 $\mu \mathrm{M}$ selenite/ml DMEM) and eugenol (250 $\mu \mathrm{M}$ of eugenol/ml DMEM) (eugenol-treated). 4) Group IV comprising lenses cultured in DMEM containing sodium selenite (100 $\mu \mathrm{M}$ selenite/ml DMEM) and nanoeugenol (150 $\mu \mathrm{M}$ of nanoeugenol/ml DMEM) (nanoeugenol-treated). Abbreviation: DMEM= Dulbecco's modified Eagle's medium; EGR 1= Early growth response protein 1; COX-1= Cytochrome c oxidase subunit I; Bcl-2= B-cell lymphoma 2; Bax= Bcl-2-associated X; GAPDH=Glyceraldehyde 3phosphate dehydrogenase. Statistical analysis: All values are expressed as mean \pm standard deviation of six determinations; One-way analysis of variance with post-hoc test [least significant difference]; a Statistically significant difference $(P<0.05)$ when compared with group I values; $b$ Statistically significant difference $(P<0.05)$ when compared with group II values. c Statistically significant difference $(P<0.05)$ 
when compared with group III values. d Statistically significant difference $(P<0.05)$ when compared with group IV values.

a)

\section{Group I Group II Group III Group IV}
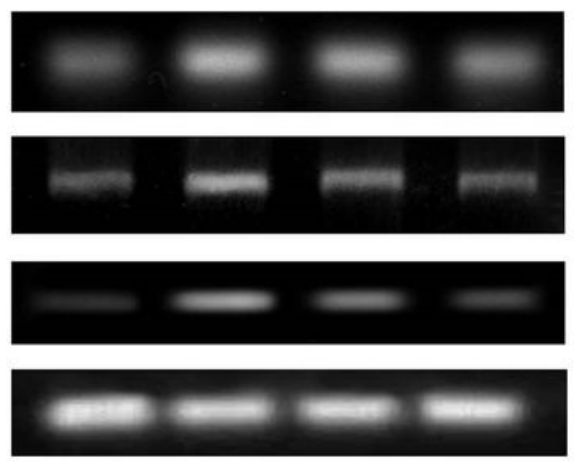

Caspase-3 (432 bps)

Caspase-8 (297 bps)

Caspase-9 (287 bps)

GAPDH (207 bps) b)

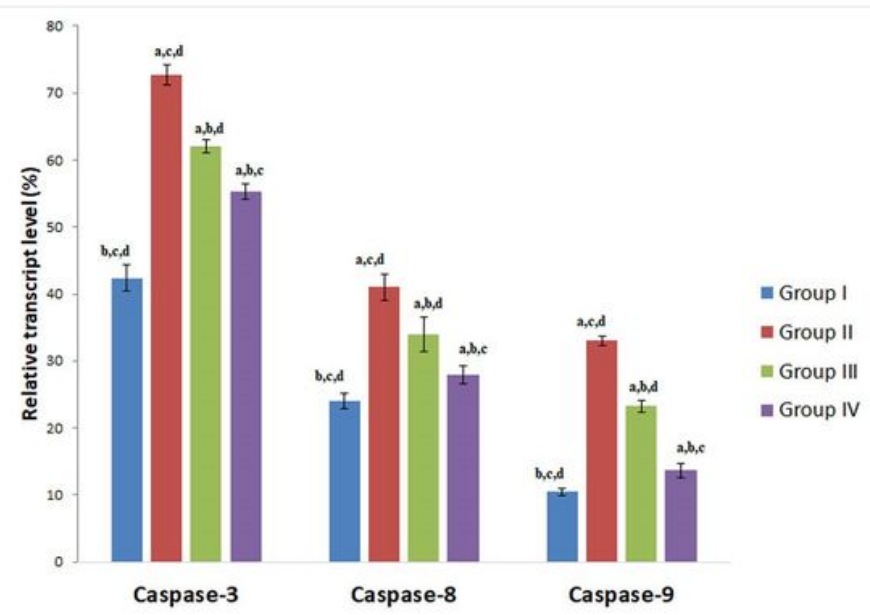

\section{Figure 3}

In-vitro study on Wistar rat lenses cultured for $24 \mathrm{~h}$ in Dulbecco's modified Eagle's medium (DMEM): RTPCR generation of mRNA transcripts of genes encoding caspase-3, caspase- 8 and caspase- 9 proteins in selenite-challenged lenses. a) Ethidium bromide-stained agarose gel showing differential staining intensity of mRNA transcripts of the genes in the four groups of lenses. b) Bar graphs of mean normalised (in relation to GAPDH) densitometry readings of mRNA transcripts of the genes in the four groups of lenses. Groups of lenses 1) Group I comprising lenses cultured in DMEM alone (normal control). 2) Group II comprising lenses cultured in DMEM containing sodium selenite only (100 $\mu \mathrm{M}$ selenite/ml DMEM) (selenite only). 3) Group III comprising lenses cultured in DMEM containing sodium selenite (100 $\mu \mathrm{M}$ selenite/ml DMEM) and eugenol (250 $\mu \mathrm{M}$ of eugenol/ml DMEM) (eugenol-treated). 4) Group IV comprising lenses cultured in DMEM containing sodium selenite (100 $\mu \mathrm{M}$ selenite/ml DMEM) and nanoeugenol (150 $\mu \mathrm{M}$ of nanoeugenol/ml DMEM) (nanoeugenol-treated). Abbreviation: DMEM= Dulbecco's modified Eagle's medium; GAPDH=Glyceraldehyde 3-phosphate dehydrogenase. Statistical analysis: All values are expressed as mean \pm standard deviation of six determinations; One-way analysis of variance with post-hoc test [least significant difference]; a Statistically significant difference $(P<0.05)$ when compared with group I values; b Statistically significant difference $(P<0.05)$ when compared with group II values. c Statistically significant difference $(P<0.05)$ when compared with group III values. $d$ Statistically significant difference $(P<0.05)$ when compared with group IV values. 
a)

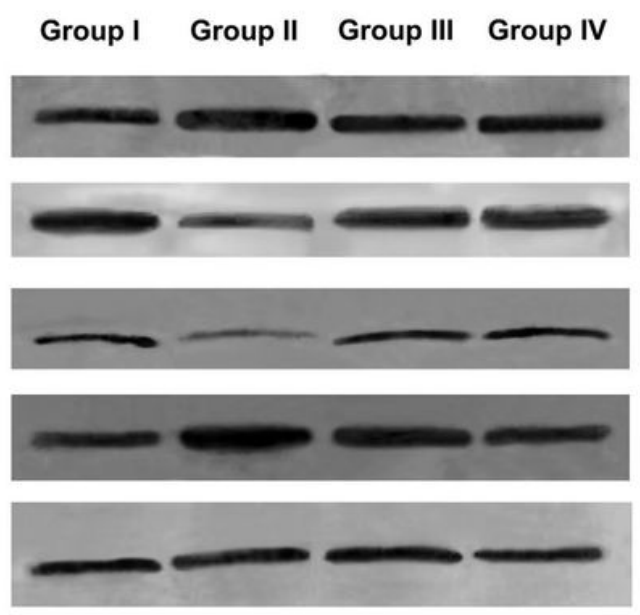

b)

EGR-1 (82 kDa)

COX-1 (72 kDa)

$\mathrm{BCl}-2$ (26 kDa)

Bax (23 kDa)

$\beta$-Actin (42 kDa)

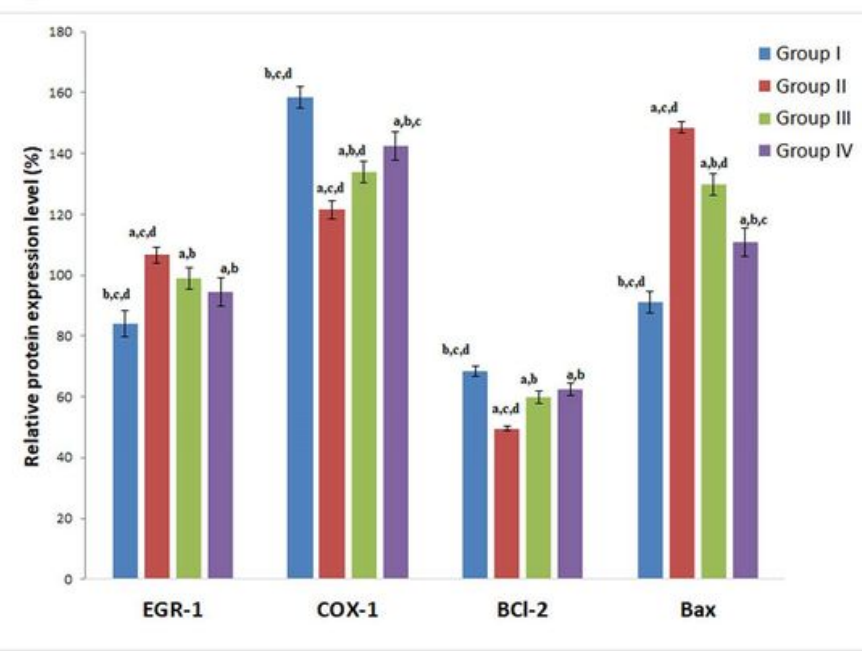

\section{Figure 4}

In-vitro study on Wistar rat lenses cultured for $24 \mathrm{~h}$ in Dulbecco's modified Eagle's medium (DMEM): immunoblot investigations on apoptotic-cascade component proteins and related proteins in selenitechallenged lenses. a) Immunoblots showing differential staining intensity of apoptotic cascade component proteins and related proteins in the four groups of lenses. b) Bar graphs of mean normalised (in relation to $\beta$-actin) densitometry readings of apoptotic cascade component proteins and related proteins in the four groups of lenses. Groups of lenses 1) Group I comprising lenses cultured in DMEM alone (normal control). 2) Group II comprising lenses cultured in DMEM containing sodium selenite only (100 $\mu \mathrm{M}$ selenite/ml DMEM) (selenite only). 3) Group III comprising lenses cultured in DMEM containing sodium selenite (100 $\mu \mathrm{M}$ selenite/ml DMEM) and eugenol $(250 \mu \mathrm{M}$ of eugenol/ml DMEM) (eugenoltreated). 4) Group IV comprising lenses cultured in DMEM containing sodium selenite (100 $\mu \mathrm{M}$ selenite/ml DMEM) and nanoeugenol (150 $\mu \mathrm{M}$ of nanoeugenol/ml DMEM) (nanoeugenol-treated). Abbreviation: DMEM= Dulbecco's modified Eagle's medium; EGR 1 = Early growth response protein 1; COX1= Cytochrome c oxidase subunit I; Bcl-2= B-cell lymphoma 2; Bax= Bcl-2-associated X. Statistical analysis: All values are expressed as mean \pm standard deviation of six determinations; One-way analysis of variance with post-hoc test [least significant difference]; a Statistically significant difference $(P<0.05)$ when compared with group I values; b Statistically significant difference $(P<0.05)$ when compared with group II values. c Statistically significant difference $(P<0.05)$ when compared with group III values. $d$ Statistically significant difference $(P<0.05)$ when compared with group IV values. 


\title{
Group I Group II Group III Group IV
}

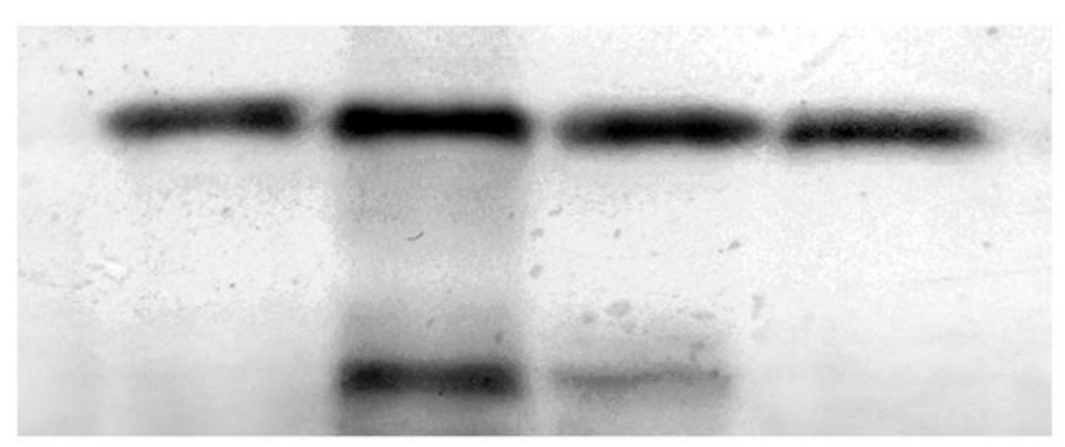

Caspase-3 (32 kDa)

Cleaved caspase-3 (17 kDa)

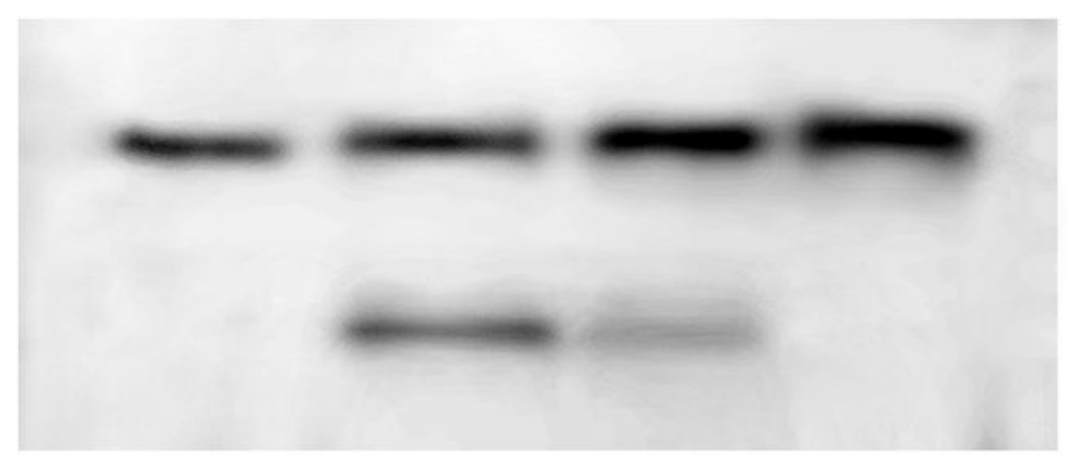

\author{
Caspase-8 (55 kDa)
}

Cleaved caspase-8 (42 kDa)

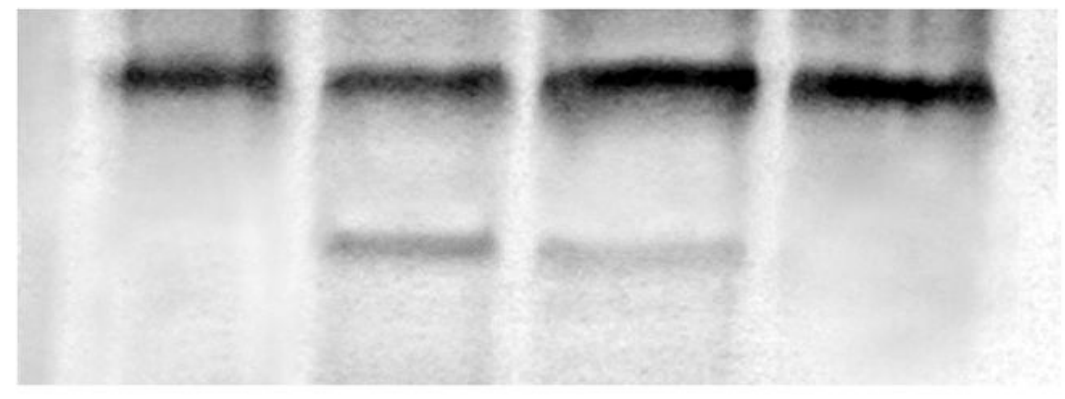

\author{
Caspase-9 (45 kDa)
}

Cleaved caspase-9 (35 kDa)

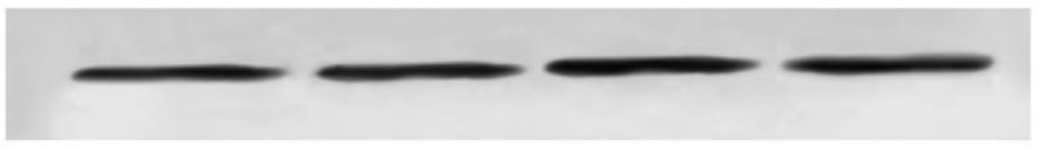

\section{$\beta$-Actin (42 kDa)}

\section{Figure 5}

In-vitro study on Wistar rat lenses cultured for $24 \mathrm{~h}$ in Dulbecco's modified Eagle's medium (DMEM): immunoblot investigations on caspase- 3 , caspase-8 and caspase-9 proteins in selenite-challenged lenses. Immunoblots showing differential staining intensity of caspase-3, caspase-8 and caspase- 9 proteins in the four groups of lenses. Groups of lenses 1) Group I comprising lenses cultured in DMEM alone (normal control). 2) Group II comprising lenses cultured in DMEM containing sodium selenite only (100 $\mu \mathrm{M}$ selenite/ml DMEM) (selenite only). 3) Group III comprising lenses cultured in DMEM containing sodium selenite $(100 \mu \mathrm{M}$ selenite/ml DMEM) and eugenol $(250 \mu \mathrm{M}$ of eugenol/ml DMEM) (eugenol- 
treated). 4) Group IV comprising lenses cultured in DMEM containing sodium selenite (100 $\mu \mathrm{M}$ selenite/ml DMEM) and nanoeugenol (150 $\mu \mathrm{M}$ of nanoeugenol/ml DMEM) (nanoeugenol-treated).
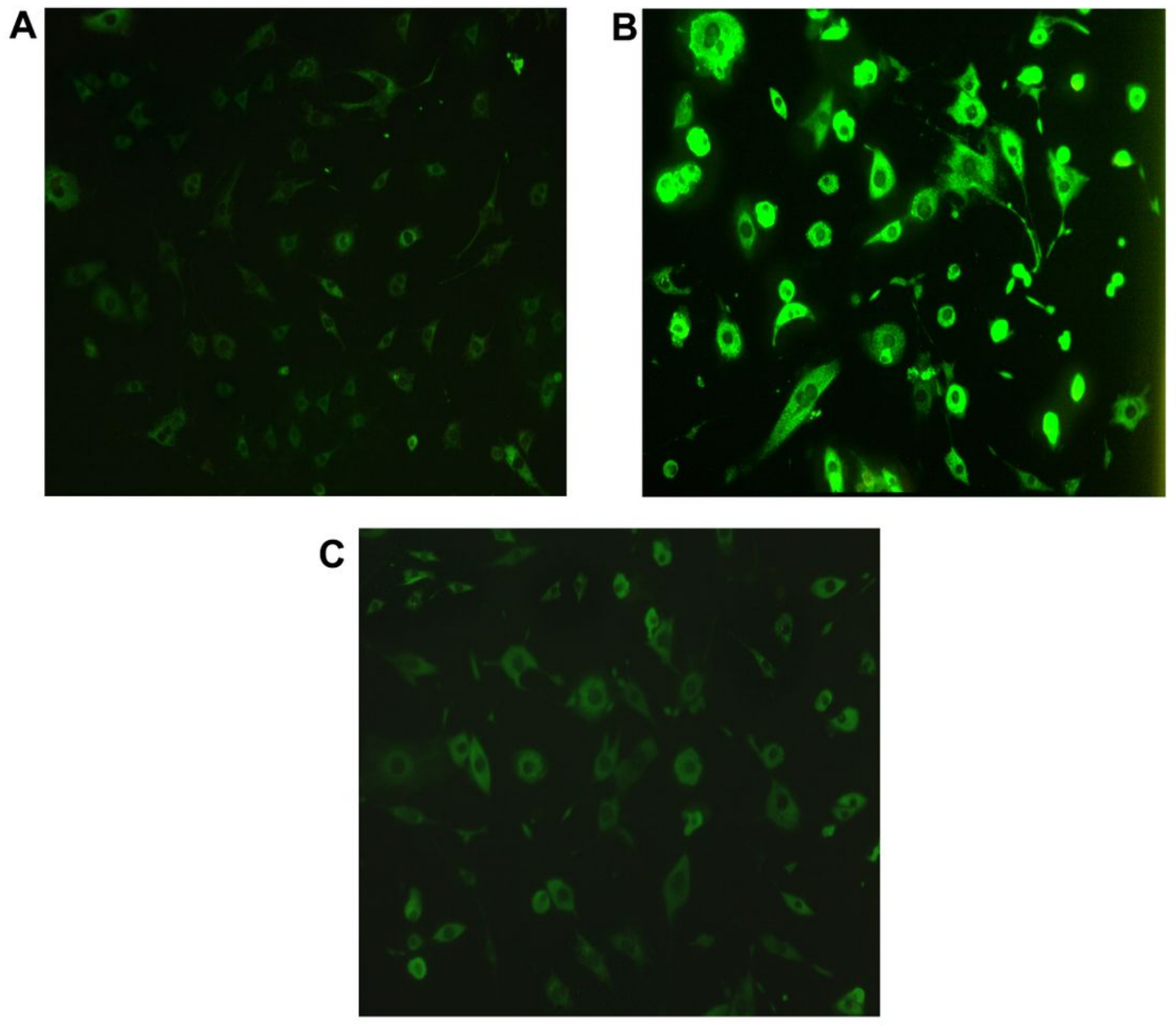

\section{Figure 6}

Study on selenite-challenged human lenticular epithelial B-3 (HLE-B3) cells: reactive oxygen species (ROS)-scavenging potential of nanoeugenol in HLE-B3 cells stained using dichlorofluorescin diacetate staining A. Group I (control) comprising HLE-B3 cells cultured in DMEM alone; B. Group II (selenite only cells) comprising HLE-B3 cells cultured in DMEM that contained sodium selenite $(16 \mu \mathrm{M}$ selenite $/ \mathrm{ml}$ of DMEM); and C. Group III (nanoeugenol-treated cells) comprising HLE-B3 cells cultured in DMEM that 
contained simultaneously exposed to sodium selenite ( $16 \mu \mathrm{M}$ selenite/ml of DMEM) and nanoeugenol (80 $\mu \mathrm{M}$ nanoeugenol / $\mathrm{ml}$ of DMEM).
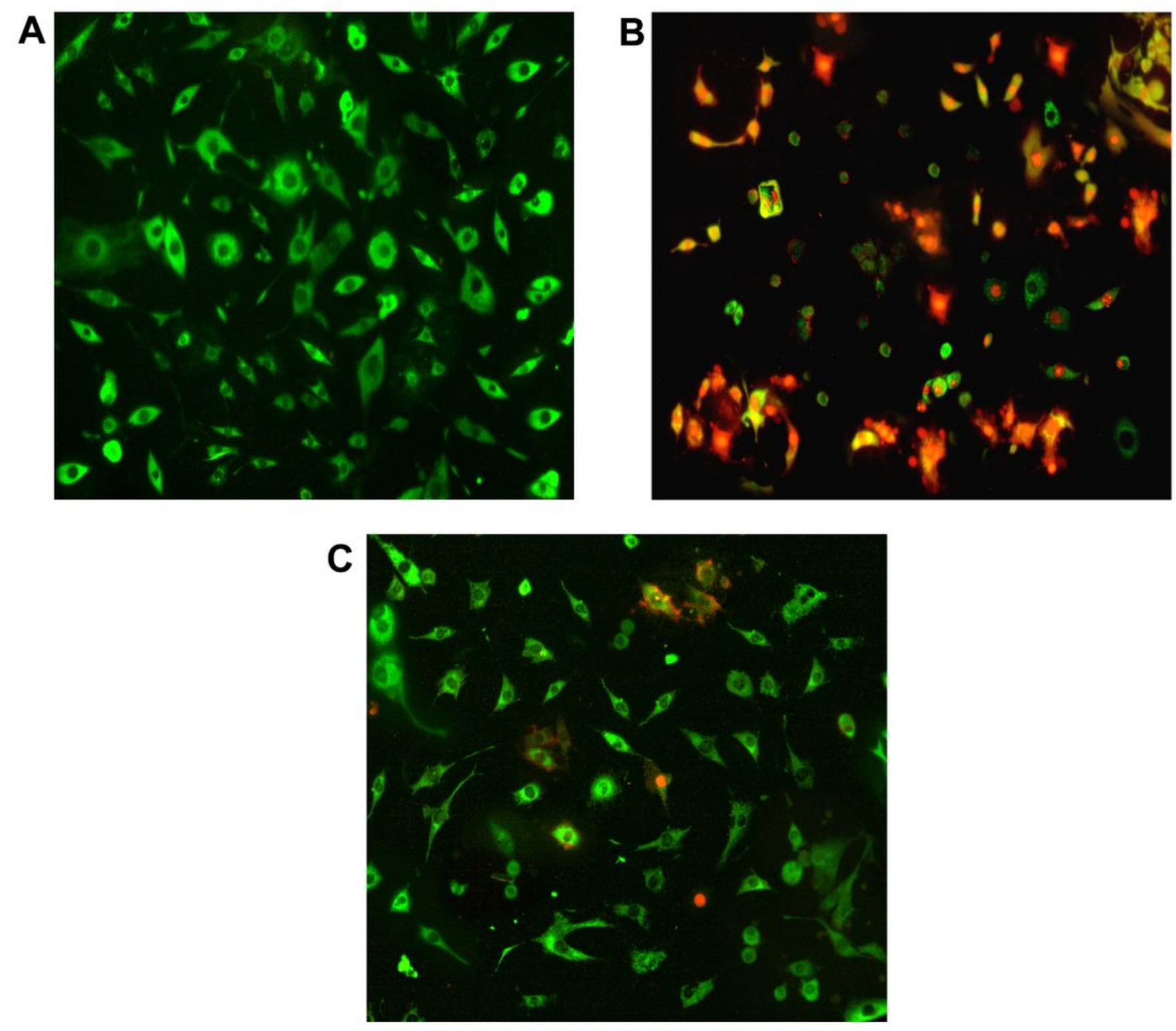

\section{Figure 7}

Study on selenite-challenged human lenticular epithelial B-3 (HLE-B3) cells: prevention of HLE-B3 cell death by nanoeugenol (cells stained by acridine orange and ethidium bromide). A. Group I (control) comprising HLE-B3 cells cultured in DMEM alone; B. Group II (selenite only cells) comprising HLE-B3 cells cultured in DMEM that contained sodium selenite (16 $\mu \mathrm{M}$ selenite/ml of DMEM); and C. Group III 
(nanoeugenol-treated cells) comprising HLE-B3 cells cultured in DMEM and simultaneously exposed to sodium selenite ( $16 \mu \mathrm{M}$ selenite/ml of DMEM) and nanoeugenol ( $80 \mu \mathrm{M}$ nanoeugenol / $\mathrm{ml}$ of DMEM). 